\title{
ESTRATÉGIA EMPRESARIAL
}

A estratégia empresarial é um campo multidisciplinar que reúne contribuições de áreas tão diversas quanto economia, teoria organizacional, sociologia, psicologia e ciência política. O estudo de estratégia empresarial é relativamente recente e, somente nos últimos anos, tem ganhado mais força no Brasil. No entanto, uma visão de estratégia empresarial é extremamente importante no contexto da globalização e das mudanças econômicas pelas quais o Brasil está passando. As indicações bibliográficas a seguir são do professor Flávio C. de Vasconcelos, do Departamento de Administração Geral e Recursos Humanos da FGV-EAESP.

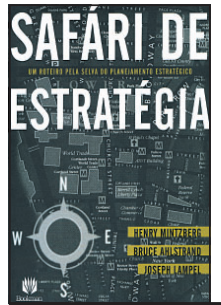

SAFÁRI DE ESTRATÉGIA: um roteiro pela selva do planejamento estratégico

Henry Mintzberg, Bruce Ahlstrand e Joseph Lampel. Porto Alegre : Bookman, 2000. 304 p.

Os autores expõem revisão bibliográfica de mais de 2.000 itens e classificam-nos em dez escolas de estratégia, das quais três são prescritivas (design, planejamento e posicionamento) e as outras sete (empreendedora, cognitiva, aprendizado, poder, cultural, ambiental e de configuração) são analíticas e descritivas. Com uma abordagem generalista, fazem um mapeamento do campo de estratégia empresarial e uma boa síntese da bibliografia da área, oferecendo uma visão multidimensional do campo de estratégia.

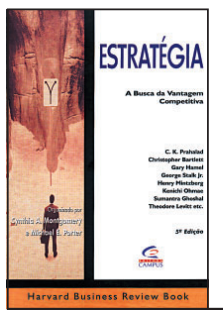

ESTRATÉGIA: a busca da vantagem competitiva

Cynthia A. Montgomery e Michael E. Porter (Orgs.). Rio de Janeiro : Campus, 1998. 528 p.

Trata-se de um volume editado por dois professores da Harvard Business School, que resume alguns dos títulos mais importantes publicados na área de estratégia nos últimos anos. Os assuntos tratados são ligados ao conceito de estratégia empresarial, à relação da estratégia competitiva com a estratégia funcional, ao cenário de competição internacional das empresas, a questões de governança e estratégia corporativa e ao processo de formulação de estratégias.

\section{ECONOMICS, ORGANIZATION \& MANAGEMENT}

Paul Milgrom e John Roberts. New Jersey : Prentice Hall, 1992. 622 p. Livro que procura explorar as interfaces entre economia - especialmente economia de custos de transação - e as disciplinas de estratégia empresarial e teoria organizacional. A obra analisa tópicos como o mecanismo de coordenação por meio do mercado ou da organização e formas de contrato, informe e incentivos. O livro aborda, também, questões ligadas ao design da firma e à evolução das empresas e dos sistemas econômicos. Trata-se de uma referência fundamental para entender as relações entre economia e estratégia.

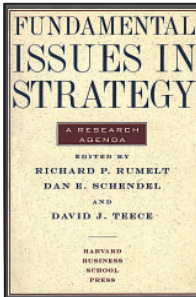

\section{FUNDAMENTAL ISSUES IN STRATEGY: a research agenda}

Richard P. Rumelt, Dan E. Schendel e David J. Teece. Boston : Harvard Business School Press, 1994. 656 p. Este livro reúne uma série de artigos de pesquisa que investigam tópicos avançados em estratégia empresarial. Entre os temas presentes, encontramos: a teoria dos jogos e a sua utilidade para a estratégia de empresas, uma discussão das razões da diferenciação entre as firmas. São também abordados as funções do centro corporativo em uma firma multidivisional e os fatores que determinam o sucesso e o fracasso das firmas em contextos de competição internacional. Apesar de ter sido publicado em 1994, a agenda proposta continua atual e relevante. 